\title{
Levantamento da flora apícola em Santa Luzia do Paruá, Sudoeste da Amazônia, Maranhão
}

\author{
Luiz Junior Pereira Marques ${ }^{1}$, Francisca Helena Muniz ${ }^{2,3}$, Gislane da Silva Lopes ${ }^{1}$ \\ e José Malheiros Silva ${ }^{1}$
}

Recebido em 16/04/2010. Aceito em 17/01/2011

\section{RESUMO}

(Levantamento da flora apícola em Santa Luzia do Paruá, Sudoeste da Amazônia, Maranhão). Foi realizado o levantamento das plantas visitadas por Apis mellifera L. através de análise polínica no município de Santa Luzia do Paruá, Maranhão, localizado a noroeste do Estado, em região amazônica. A temperatura média anual varia entre $26^{\circ} \mathrm{C}$ e $27^{\circ} \mathrm{C}$, com umidade relativa do ar anual entre 79 a $82 \%$ e precipitação pluviométrica entre 2000 a $2400 \mathrm{~mm}$ anuais. O estudo foi conduzido entre agosto de 2005 e julho de 2006 em três apiários da região, com coletas mensais de mel, pólen e plantas, que foram submetidas ao método de acetólise. Os tipos polínicos das amostras de mel foram identificados e contados para a determinação da freqüência relativa média. Nas amostras de pólen foi realizada apenas a identificação dos tipos polínicos por meio da comparação com os polens das plantas (botões florais) depositados em coleção de referência. As principais famílias utilizadas por A. mellifera foram Amaranthaceae, Arecaceae, Asteraceae, Urticaceae, Euphorbiaceae, Lamiaceae, Fabaceae-Mimosoideae, Flacourtiaceae, Myrtaceae, Poaceae e Rubiaceae. Em amostras de mel, no período chuvoso destacaram-se os tipos polínicos de Mimosa pudica, Borreria e um tipo indeterminado da família Arecaceae. No período de safra foram representativos Hyptis e um tipo indeterminado de Asteraceae. Os tipos polínicos mais constantes nas amostras de pólen foram Euterpe oleracea, Asteraceae tipo 1, Mimosa pudica e Borreria.

Palavras-chave: Amazônia Maranhense, flora, inventário, mel, pólen

\begin{abstract}
(Survey of bee flora in Santa Luzia do Paruá, Southwest Amazonia, Maranhão). The plant species visited by Apis mellifera L. were surveyed by pollen analysis in Santa Luzia do Paruá municipality, located in northwestern Maranhão state. Natural vegetation is Amazon rainforest, mean annual temperature varies between $26^{\circ} \mathrm{C}$ and $27^{\circ} \mathrm{C}$, relative air humidity between 79 and $82 \%$, and total rainfall between 2000 and $2400 \mathrm{~mm}$. This study was conducted from August 2005 to July 2006 in three apiaries of the region, with monthly sampling of honey, pollen and plants. The samples were analyzed by the acetolysis method. The pollen types were identified and counted in honey samples to determine mean frequency of the three apiaries. In the pollen samples, pollen types were identified by comparison with the pollen of plants (flower buds) deposited in the reference collection. The main plant families used as floral resource by A. mellifera are Amaranthaceae, Arecaceae, Asteraceae, Urticaceae, Euphorbiaceae, Lamiaceae, Fabaceae-Mimosoideae, Flacourtiaceae, Myrtaceae, Poaceae and Rubiaceae. In the honey samples, the pollen types of Mimosa pudica, Borreria and members of the Arecaceae family were most important during the rainy season. At harvest time (transition between rainy and dry season), Hyptis, Borreria, and an undetermined pollen type of the Asteraceae family were most important. The pollen types that show major constancy in the sample pollen were Euterpe oleracea, Asteraceae type 1, Mimosa pudica and Borreria.
\end{abstract}

Key words: Amazonia maranhense, Flora, Floristic inventory, Honey, Pollen

\footnotetext{
1 Universidade Estadual do Maranhão, Agrônomo, Mestre em Agroecologia, São Luis, MA, Brasil

2 Universidade Estadual do Maranhão, Centro de Educação Ciências Exatas e Naturais, Departamento de Química e Biologia, São Luis, MA, Brasil

3 Autor para correspondência: fhmuniz@yahoo.com
} 


\section{Introdução}

A Apicultura é uma atividade econômica conservadora de espécies, porque permite a utilização permanente dos recursos naturais e a não destruição do meio rural (Reis \& Cosmastri Filho 2003). Entretanto, a falta de estudos que indiquem as principais espécies de interesse apícola tornase um entrave para o desenvolvimento desta atividade e, consequentemente da produção do mel.

O conhecimento das plantas de uma região, bem como sua época de florescimento e as características do pólen, auxiliam na determinação das espécies vegetais que contribuem para composição do mel (Marchini et al. 2001), e é importante para desencadear procedimentos de manejo da colméia que poderão maximizar a exploração do fluxo de néctar e pólen (Salomé \& Orth 2003). De acordo com Barth (2005), a qualidade do mel depende de um lado de sua composição química, principalmente quanto aos diferentes tipos de açucares, sais minerais, proteínas e água; e por outro lado, dos grãos de pólen provenientes, na sua maior parte, das plantas fornecedoras de néctar.

Como uma determinada espécie vegetal pode apresentar características diferenciadas no fornecimento de recursos florais para as abelhas em função das condições edafoclimáticas, o inventário da flora apícola deve ser regional, uma vez que as espécies consideradas excelentes produtoras de néctar em uma região podem não o ser em outra (Ferreira 1981; Carvalho \& Marchini 1999; Santos et al. 2006).

A vegetação do estado do Maranhão reflete os aspectos transicionais do clima e das condições edáficas da região, apresentando desde ambientes salinos com presença de manguezais, campos inundáveis, cerrados e babaçuais, até vegetação florestal com características amazônicas. Este aspecto torna-se muito interessante para a atividade apícola devido à diversidade de espécies disponíveis nas diferentes situações de habitats, que podem proporcionar grande disponibilidade de néctar e pólen.

O levantamento da flora apícola possibilita observar as peculiaridades dos ecossistemas maranhenses associados à apicultura, para determinar o potencial produtivo e determinar as possibilidades de manejo, considerando que a diversidade da flora permite uma apicultura sustentável e rentável.

Neste estudo foi realizado o levantamento da flora apícola em Santa Luzia do Paruá, município compreendido na Amazônia Maranhense, relacionando o período das floradas e o mel produzido, com o objetivo de estimar o potencial do pasto apícola e indicar os recursos florais mais utilizados para néctar e pólen na região.

\section{Material e métodos}

O estudo foi conduzido no município de Santa Luzia do Paruá (02³2’36,2" S e 4546’26,9” W), localizado a noroeste do Estado, na microrregião do Pindaré. A temperatura mé- dia anual varia entre $26^{\circ} \mathrm{C}$ e $27^{\circ} \mathrm{C}$, com umidade relativa do ar anual entre $79 \%$ e $82 \%$ e a precipitação pluviométrica apresenta totais entre 2000 a $2400 \mathrm{~mm}$ anuais; possui clima bem definido com o período chuvoso iniciando em meados do mês de janeiro até julho, quando inicia o período seco, compreendido entre agosto e dezembro (Geplan 2002) (Fig. 1). O período de produção de mel, de acordo com os produtores locais, vai de julho a outubro e uma pequena produção no final do mês de janeiro.

Foram realizadas coletas e observações diretas mensais ao longo do ano das espécies de plantas em floração, em um raio de $1.500 \mathrm{~m}$ a partir das colméias. $\mathrm{O}$ material botânico foi herborizado para montagem de exsicatas e identificação das espécies no Herbário da UEMA em São Luís. O sistema de classificação adotado para o nível de família foi o APG III (2009), com exceção da família Flacourtiaceae (Cronquist, 1981). As espécies foram identificadas com literatura apropriada e orientação de especialistas. Também foi definido o estrato de forrageamento das abelhas: arbóreo, arbustivo e herbáceo. O estrato arbóreo caracterizado pelas formas vegetativas lenhosas de tronco robusto, em regra com um sistema de ramos divaricados de primeira ordem, a partir de um certo nível, de onde se dispõem as ramificações de copa, atingindo todo o corpo vegetativo altura superior a 5 $\mathrm{m}$. O estrato arbustivo caracterizado pelas formas vegetais lenhosas possuidoras de um pequeno suporte, de 3-5 m de altura, com ramificações numerosas ao longo de seu eixo simples, a partir de suas porções inferiores. O estrato herbáceo se caracteriza pelas formas vegetais pequenas, delicadas, eretas, em regra clorofilada e anual, podendo apresentar um curtíssimo eixo herbáceo (Fernandes 2007).

As coletas de mel ( $5 \mathrm{ml}$ de mel verde) e cargas de pólen ocorreram mensalmente, no período de agosto de 2005 a julho de 2006, em três colônias distribuídas em três apiários. $\mathrm{O}$ mel verde foi retirado diretamente do favo e as cargas de pólen foram coletadas através de coletor de pólen. $\mathrm{O}$ mel "verde" é aquele mel ainda não-maduro com altos índices de umidade que as abelhas ainda não opercularam (Pereira et al. 2003).

Todas as amostras de mel e carga de pólen foram acetolisadas segundo Erdtman (1952) e montadas em lâminas para observação em microscópio seguindo o método de Maurizio \& Louveaux (1965). Todo o procedimento foi realizado no laboratório de Química da Universidade Estadual do Maranhão. Os tipos polínicos foram desenhados a mão livre com caracteres de abertura e detalhes de exina em folha de papel A4 para organização da contagem a partir de observações em microscópio Zeiss com aumento de 400 a 1000 vezes.

Para cada amostra de mel foram contados 300 a 500 grãos de pólen, mensalmente, calculando-se a freqüência relativa para cada apiário e, posteriormente a freqüência relativa média dos três apiários nas amostras de mel. Os grãos de pólen foram classificados em pólen dominante ( $\mathrm{PD}>45 \%$ do total de grãos), pólen 


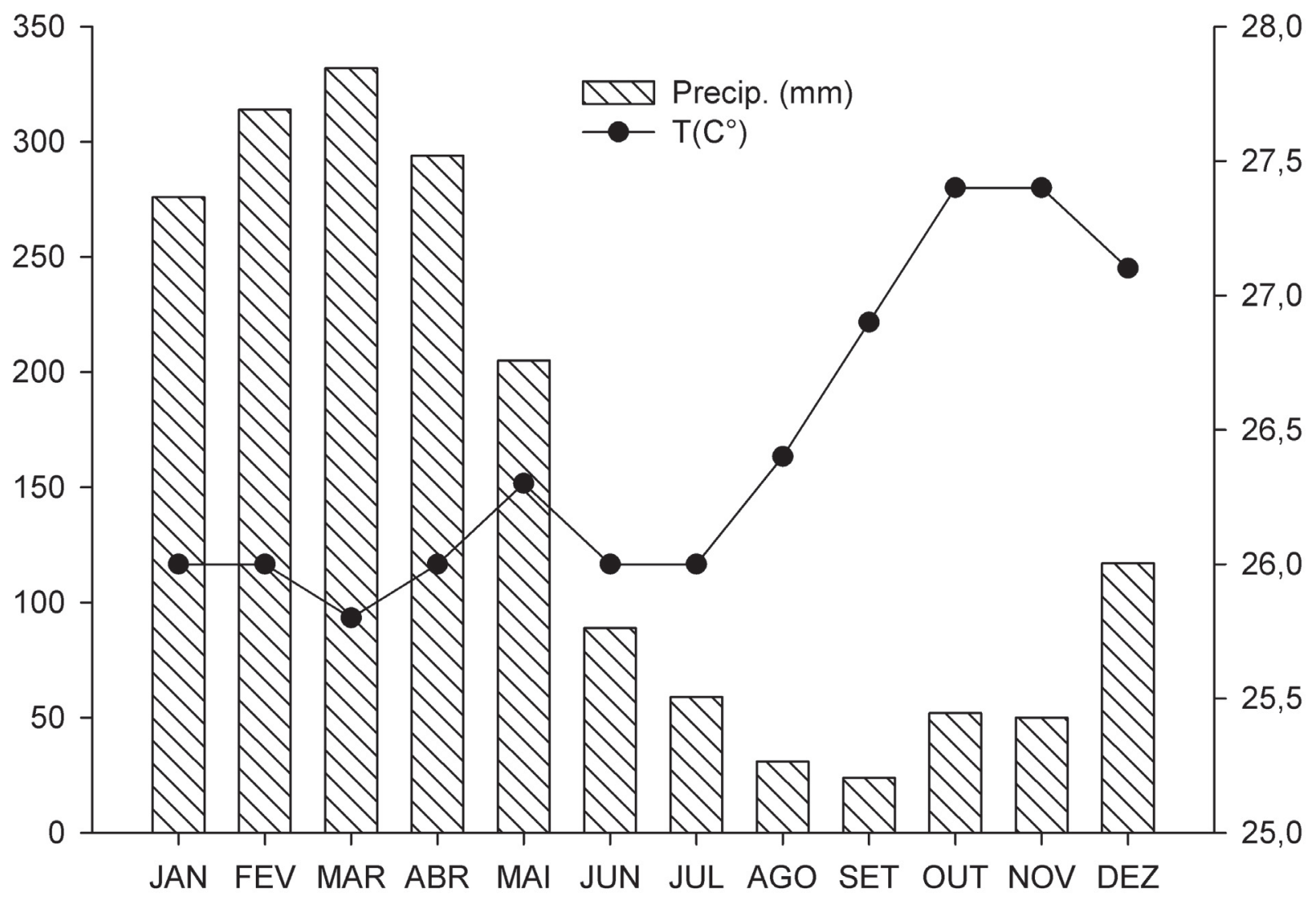

Figura 1. Dados climatológicos (precipitação e temperatura) da região leste maranhense, média histórica de 39 anos (1961-1991). Fonte: Laboratório de Meteorologia, LABMET/UEMA, http://www.nemrh.uema.br/index.html. (Acesso em 08 de dezembro de 2010).

acessório (PA de 15\% a 45\%) e pólen isolado ( $\mathrm{PI}<15 \%)$ (Oliveira et al., 1998).

Nas amostras das cargas de pólen foram escolhidas ao acaso quatro bolotas de pólen do material coletado para o processo de acetólise com apenas identificação dos tipos polínicos (presença e ausência).

As lâminas de referência foram confeccionadas a partir dos botões florais através do processo de acetólise. A identificação dos tipos polínicos foi realizada por comparação com lâminas de referência, além da utilização de material especializado (Mendonça et al. 2008; Luz et al. 2007; Roubik \& Patiño 2003; Moreti et al. 2000; Oliveira et al. 1998; Barth et al. 1998). Assim, foi dada atenção às espécies botânicas coletadas na área que se correlacionavam com as lâminas de mel e pólen.

\section{Resultados e discussão}

\section{Tipos polínicos no mel}

No mel observou-se um maior número de tipos polínicos em relação às amostras de pólen, o que pode estar relacionado com o processo de coleta das abelhas. As abelhas coletam néctar das flores do campo e os grãos de pólen são ocasionalmente engolidos pelas abelhas e levados para dentro da colméia, onde são transformados junto com o néctar em mel e estocados nos alvéolos (Barth, 2004).

Nas amostras de mel foram identificadas 12 famílias, 12 gêneros, nove espécies e cinco tipos indeterminados, perfazendo um total de 22 tipos polínicos. O forrageamento das abelhas ocorreu nos extrato arbustivo $(11,76 \%)$ e principalmente nos extratos herbáceo $(41,17 \%)$ e arbóreo $(47,05 \%)$, sendo que todos os tipos polínicos identificados no mel e no pólen pertencem às espécies coletadas no raio de $1500 \mathrm{~m}$. No entanto é no extrato herbáceo que se encontra os maiores percentuais médios de Freqüência Relativa de tipos polínicos (Tabela 1) e provavelmente estes são os maiores contribuidores na produção de mel nessa região.

Foram identificadas 20 famílias, 30 gêneros e 34 espécies em floração nos três apiários na vegetação dentro do raio de $1500 \mathrm{~m}$. Vários estudos têm revelado um padrão comum de exploração dos recursos florais por A. mellifera, que visita um amplo espectro de plantas e concentra o forrageamento em poucas espécies (Aguiar et al. 2002).

As principais famílias representadas nas amostras de mel foram Amaranthaceae, Arecaceae, Asteraceae, Urticaceae, Euphorbiaceae, Lamiaceae, Fabaceae-Mimosoideae, Flacourtiaceae (sensu Cronquist, 1981), Myrtaceae, Poaceae, Rubiaceae. Segundo Ramalho et al. (1990), as famílias 
Tabela 1. Média da Freqüência (\%) dos tipos polínicos das amostras de mel coletadas por A. mellifera L., em três apiários no município de Santa Luiza do Paruál MA, durante o período de agosto/2005 a julho/2006.

\begin{tabular}{|c|c|c|c|c|c|c|c|c|c|c|c|c|c|c|}
\hline \multirow[b]{2}{*}{ Tipos polínicos } & \multirow[b]{2}{*}{$\begin{array}{c}\text { Nome } \\
\text { popular }\end{array}$} & \multirow[b]{2}{*}{ Porte } & \multirow[b]{2}{*}{ Ago } & \multicolumn{4}{|c|}{2005} & \multicolumn{7}{|c|}{2006} \\
\hline & & & & Set & Out & Nov & Dez & Jan & Fev & Mar & Abr & Mai & Jun & Jul \\
\hline \multicolumn{15}{|l|}{ Amaranthaceae } \\
\hline Alternanthera brasiliana & Carrapicho & Herbácea & 0,00 & 2,96 & 0,00 & 0,00 & 0,00 & 0,00 & 0,00 & 0,00 & 0,00 & 0,00 & 0,00 & 0,00 \\
\hline \multicolumn{15}{|l|}{ Arecaceae } \\
\hline Euterpe oleracea & Juçara & Arbóreo & 1,29 & 0,43 & 28,42 & 2,94 & 0,00 & 0,25 & 0,23 & 0,72 & 0,00 & 0,21 & 0,60 & 1,35 \\
\hline Mauritia flexuosa & Buriti & Arbóreo & 0,00 & 0,00 & 0,00 & 2,94 & 0,00 & 0,56 & 0,29 & 0,00 & 0,23 & 0,00 & 0,00 & 0,00 \\
\hline Maximiliana maripa & Inajá & Arbóreo & 0,68 & 0,00 & 1,47 & 1,35 & 0,53 & 0,00 & 0,00 & 0,00 & 0,00 & 0,00 & 0,00 & 0,15 \\
\hline Orbignya phalerata & Babaçu & Arbóreo & 0,00 & 0,24 & 31,65 & 0,00 & 0,00 & 0,00 & 0,19 & 0,00 & 0,00 & 0,00 & 0,00 & 0,00 \\
\hline \multicolumn{15}{|l|}{ Asteraceae } \\
\hline Tipo indet. & & Arbusto & 0,58 & 0,73 & 7,18 & 0,31 & 7,21 & 8,27 & 0,41 & 0,17 & 0,00 & 0,00 & 0,21 & 3,33 \\
\hline \multicolumn{15}{|l|}{ Euphorbiaceae } \\
\hline Tipo indet. & & Herbácea & 0,00 & 61,59 & 0,00 & 2,35 & 2,42 & 0,45 & 0,12 & 0,00 & 0,00 & 0,00 & 0,00 & 0,15 \\
\hline \multicolumn{15}{|l|}{ Fabaceae-Mimosoideae } \\
\hline Mimosa caesalpiniifolia & Sabiá & Arbóreo & 0,27 & 2,17 & 0,29 & 6,5 & 1,84 & 0,75 & 1,77 & 8,28 & 8,99 & 2,65 & 0,45 & 1,51 \\
\hline Mimosa pudica & Sensitiva & Herbácea & 17,15 & 7,37 & 5,05 & 13,55 & 18,47 & 23,02 & 62,47 & 84,19 & 85,71 & 32,05 & 14,85 & 35,04 \\
\hline Stryphnodendron & Fava de paca & Arbóreo & 0,00 & 0,00 & 0,00 & 0,00 & 0,00 & 1,36 & 0,92 & 0,00 & 0,00 & 0,00 & 0,00 & 0,00 \\
\hline \multicolumn{15}{|c|}{ Flacourtiaceae (sensu Cronquist, 1981) } \\
\hline Tipo indet. & & & 0,00 & 33 & 0,00 & 3,53 & 17,48 & 74,74 & 13,87 & 2,95 & 0,4 & 0,00 & 0,00 & 0,00 \\
\hline \multicolumn{15}{|l|}{ Lamiaceae } \\
\hline Hyptis & & Herbácea & 19,46 & 5,15 & 2,56 & 0,62 & 0,00 & 1,67 & 0,46 & 1,68 & 0,00 & 76,84 & 65,94 & 37,74 \\
\hline \multicolumn{15}{|l|}{ Myrtaceae } \\
\hline Tipo indet. & & Arbóreo & 1,86 & 5,06 & 1,54 & 7,96 & 12,68 & 0,66 & 0,97 & 0,63 & 0,00 & 0,24 & 0,42 & 1,71 \\
\hline \multicolumn{15}{|l|}{ Poaceae } \\
\hline Zea mays & Milho & Herbácea & 0,00 & 0,97 & 0,00 & 7,35 & 0,00 & 3,79 & 3,11 & 3,17 & 1,15 & 1,93 & 0,00 & 0,00 \\
\hline \multicolumn{15}{|l|}{ Rubiaceae } \\
\hline Borreria & Vassourinha & Herbáceo & 3,62 & 29,19 & 18,84 & 3,28 & 44,18 & 18,98 & 10,35 & 6,54 & 2,07 & 2,59 & 0,23 & 9,38 \\
\hline \multicolumn{15}{|l|}{ Turneraceae } \\
\hline Turnera ulmifolia & Chanana & Herbácea & 0,00 & 0,00 & 0,00 & 2,06 & 0,27 & 0,44 & 0,23 & 0,00 & 0,00 & 0,00 & 0,00 & 0,00 \\
\hline \multicolumn{15}{|l|}{ Urticaceae } \\
\hline Cecropia & Embaúba & Arbóreo & 3,51 & 6,86 & 31,64 & 47,09 & 3,82 & 2,51 & 7,04 & 0,63 & 0,92 & 0,00 & 0,00 & 4,09 \\
\hline TIPO INDET 1 & & & 0,00 & 0,00 & 0,00 & 0,00 & 0,00 & 0,00 & 0,00 & 0,00 & 0,00 & 0,00 & 3,13 & 11,50 \\
\hline TIPO INDET 2 & & & 0,00 & 0,00 & 0,00 & 0,00 & 0,00 & 0,00 & 0,00 & 0,00 & 0,00 & 0,00 & 16,64 & 0,40 \\
\hline TIPO INDET 3 & & & 0,00 & 0,00 & 0,00 & 0,00 & 0,00 & 0,00 & 0,00 & 0,00 & 0,00 & 0,00 & 0,00 & 1,78 \\
\hline TIPO INDET 4 & & & 0,00 & 0,00 & 0,00 & 0,00 & 0,00 & 0,00 & 0,00 & 0,00 & 0,00 & 0,00 & 0,00 & 0,59 \\
\hline TIPO INDET 5 & & & 0,00 & 0,00 & 0,00 & 0,00 & 0,00 & 0,00 & 0,00 & 0,00 & 0,00 & 0,00 & 0,00 & 0,71 \\
\hline
\end{tabular}


Leguminosae, Myrtaceae, Arecaceae e Rubiaceae são as mais importantes para as abelhas africanizadas. Neste trabalho, os tipos polínicos que apresentaram os maiores percentuais médios de freqüência relativa durante o período de estudo (agosto de 2005 a julho de 2006) pertencem a família Lamiaceae (Hiptis), Fabaceae-Mimosoideae (Mimosa) e Rubiaceae (Borreria). Os tipos polínicos que mais ocorreram, nas amostras de mel, no período de estudo pertencem a família Arecaceae (Euterpe oleraceae Mart.), Asteraceae, Lamiaceae (Hiptis), Fabaceae-Mimosoideae (Mimosa caesalpinifolia, Mimosa pudica), Myrtaceae e Rubiaceae (Borreria).

\section{Tipos polínicos nas cargas de pólen}

Nas cargas de pólen foi observada maior homogeneidade em cor com poucos tipos polínicos. Nas amostras de pólen foram identificadas 14 famílias, 11 gêneros, nove espécies, perfazendo um total de 16 tipos polínicos. $\mathrm{O}$ forrageamento das abelhas, assim como nas amostras de mel foi mais expressivo nos extratos herbáceo $(42,85 \%)$ e arbóreo (42,85\%) e menos expressivo no extrato arbustivo $(14,28 \%)$, sendo que todos os tipos polínicos identificados no mel e no pólen pertencem às espécies coletadas no raio de $1500 \mathrm{~m}$.

As principais famílias nas cargas de pólen são semelhantes as das lâminas de mel, no entanto os tipos polínicos com maior ocorrência no período de estudo pertence a família Arecaceae (Euterpe oleraceae), Asteraceae, Cecropiaceae (Cecropia), Poaceae (Zea mays) e Rubiaceae (Borreria) (Tabela 2). Segundo Muniz \& Brito (2007), os tipos polínicos destas famílias também constituíram importantes recursos de pólen e mel no município de Itapecuru Mirim.

\section{Fatores ambientais (precipitação e temperatura) e recurso floral}

Através de observações de campo, junto aos produtores e das características climatológicas, a região de Santa Luzia do Paruá foi classificada em três períodos. O primeiro é o de safra que vai de junho a setembro, compreendendo o final das chuvas a início do período seco, período de transição (Geplan, 2002). Neste período contribuíram para a produção de mel, Asteraceae tipo 1, Alternanthera spp, Borreria, Euterpe oleracea, Hyptis, Maximiliana maripa, Mimosa caesalpiniifolia, Mimosa pudica, Myrtaceae tipo 1, Stryphnodendron e cinco tipos indeterminados.

O período seguinte compreende toda a estação seca ao início das chuvas, nos meses de outubro a janeiro. Geplan (2002) relaciona o período de setembro a novembro como período seco e de ocorrência das mais altas temperaturas para esta região. Neste intervalo a vegetação é raleada devido à seca e a produção de mel é reduzida. Nesta ocasião os tipos polínicos de Asteraceae tipo 1, Euphorbiaceae tipo 1, Euterpe oleracea, Borreria, Flacourtiaceae tipo 1, Hyptis, Orbignya phalerata, Mauritia flexuosa, Maximiliana maripa, Mimosa caesalpiniifolia, Mimosa pudica, Myrtaceae tipo 1, Stryphnodendron e Turnera ulmifolia contribuíram para fornecimento de néctar. Nessa época é comum os apicultores migrarem com suas colméias para as regiões de mangue e retornarem no início das chuvas, porém aqueles que permanecem no local obtêm uma pequena produção no início das chuvas.

De fevereiro a maio há o climax do período chuvoso (Geplan, 2002) e novamente ocorre a falta de recursos florais, com dificuldade no manejo dos apiários e redução na produção. Neste período foram encontrados nas amostras de mel os tipos polínicos: Asteraceae tipo 1, Euphorbiaceae tipo 1, Euterpe oleraceae, Borreria, Flacourtiaceae tipo 1, Hyptis, Orbignya phalerata, Mauritia flexuosa, Mimosa caesalpiniifolia, Mimosa pudica, Myrtaceae tipo 1, Stryphnodendron e Turnera ulmifolia, sendo estas importantes na manutenção dos apiários.

\section{As plantas e o uso dos recursos}

A família Arecaceae está representada na área por Astrocaryum vulgare, Euterpe oleracea Mart., Maximiliana maripa (Aubl.) Drude, Mauritia flexuosa L. e Orbignya phalerata Mart., palmeiras tipicamente nativas, identificadas nas amostras de mel e pólen, com exceção de $M$. flexuosa que ocorreu apenas nas lâminas de mel. O tipo polínico dessa família também foi encontrado nas amostras de mel proveniente dos municípios de Itaparica, Rio Real e Santo Antônio de Jesus no Estado da Bahia (Moreti et al., 2000).

Neste trabalho, E. oleracea, $M$. flexuosa, $M$. maripa e $O$. phalerata foram classificados como pólen isolado (PI) nas amostras de mel com exceção do mês de outubro, quando E. oleracea e $O$. phalerata apresentaram percentuais médios de $28,42 \%$ e $31,65 \%$, respectivamente. Em trabalhos de Carreira \& Jardim (1994), tipos polínicos de Arecaceae e Mauritia sp ocorrem como PI na maioria dos municípios estudados, com exceção do município de Vigia, onde o tipo polínico de Arecaceae se apresentou como pólen acessório. Moreti et al. (2000) também observaram a baixa freqüência do tipo polínico da família Palmae, assim como Carreira et al. (1986) observaram baixa freqüência de Mauritia sp. No que se refere às amostras de pólen, E. oleracea contribuiu em dez dos 12 meses avaliados.

Asteraceae também constitui uma importante fonte de néctar e pólen. As principais espécies encontradas nas áreas de estudo foram Emilia coccinia (Sims) F. Don, Mikania cordifolia (L. F.) Willd., Vernonia scorpioides (Lam.) Pers e Vernonia sp. Carvalho \& Marchini (1999) encontraram apenas duas espécies no município de Castro Alves, no estado da Bahia. Ramalho et al. (1990) identificaram 41 espécies desta família, sendo utilizadas como recurso por A. mellifera, Trigonini e Melipona; constituindo assim, uma das mais ricas em número de espécies e mais visitadas por abelhas sociais em diferentes regiões. Nas amostras de pólen foi constatado a importância de Asteraceae tipo 1 por ocorrer em oito dos 12 meses avaliados. Nas amostras de mel, os tipos polínicos desta família contribuíram durante 
Tabela 2. Presença e ausência dos tipos polínicos das espécies vegetais nas amostras de mel e pólen coletados por Apis mellifera L. em três apiários no município de Santa Luiza do Paruá/MA, durante o período de agosto/2005 a julho/2006. P (pólen dos coletores), N (pólen nas amostras de mel).

\begin{tabular}{|c|c|c|c|c|c|c|c|c|c|c|c|c|c|c|}
\hline \multirow[b]{2}{*}{ Tipos polínicos } & \multirow[b]{2}{*}{ Nome popular } & \multirow[b]{2}{*}{ Porte } & \multicolumn{6}{|c|}{2005} & \multicolumn{6}{|c|}{2006} \\
\hline & & & Ago & Set & Out & Nov & Dez & Jan & Fev & Mar & Abr & Mai & Jun & Jul \\
\hline \multicolumn{15}{|l|}{ Amaranthaceae } \\
\hline Alternanthera brasiliana & Carrapicho & Herbácea & ------ & NP & $\mathrm{P}$ & ------ & ------ & ----- & ----- & $\mathrm{P}$ & ------ & $\mathrm{P}$ & ------ & ----- \\
\hline \multicolumn{15}{|l|}{ Apocynaceae } \\
\hline Mandevilla hirsuta & & & $\mathrm{P}$ & ------ & ----- & ----- & ----- & ----- & ----- & ------ & ------ & ----- & ------ & ------ \\
\hline \multicolumn{15}{|l|}{ Arecaceae } \\
\hline Euterpe oleracea & Juçara & Arbóreo & $\mathrm{NP}$ & NP & $\mathrm{NP}$ & NP & ----- & NP & $\mathrm{N}$ & $\mathrm{NP}$ & $\mathrm{P}$ & $\mathrm{NP}$ & $\mathrm{NP}$ & NP \\
\hline Mauritia flexuosa & Buriti & Arbóreo & ------ & ------ & ----- & $\mathrm{N}$ & ----- & $\mathrm{N}$ & $\mathrm{N}$ & ------ & $\mathrm{N}$ & ----- & ------ & ----- \\
\hline Maximiliana maripa & Inajá & Arbóreo & $\mathrm{N}$ & $\mathrm{P}$ & NP & NP & $\mathrm{N}$ & --.--- & ----- & ----- & --.--- & ----- & ------ & ----- \\
\hline Orbignya phalerata & Babaçu & Arbóreo & ------ & $\mathrm{P}$ & NP & $\mathrm{P}$ & ------ & ----- & $\mathrm{N}$ & ------ & ----- & ----- & ------ & ------ \\
\hline \multicolumn{15}{|l|}{ Asteraceae } \\
\hline Tipo indet. & & Arbusto & NP & NP & $\mathrm{PN}$ & NP & $\mathrm{N}$ & $\mathrm{PN}$ & $\mathrm{NP}$ & $\mathrm{NP}$ & $\mathrm{P}$ & ----- & ------ & ----- \\
\hline \multicolumn{15}{|l|}{ Urticaceae } \\
\hline Cecropia & Embaúba & Arbóreo & ------ & ----- & ----- & ----- & $\mathrm{P}$ & $\mathrm{P}$ & ----- & $-\cdots---$ & ----- & ----- & ----- & $\mathrm{P}$ \\
\hline \multicolumn{15}{|l|}{ Euphorbiaceae } \\
\hline Tipo indet. & & Herbácea & ------ & NP & $\mathrm{P}$ & $\mathrm{N}$ & NP & NP & $\mathrm{N}$ & ------ & ----- & ----- & ----- & ----- \\
\hline \multicolumn{15}{|l|}{ Fabaceae-Mimosoideae } \\
\hline Mimosa caesalpiniifolia & Sabiá & Arbóreo & $\mathrm{N}$ & $\mathrm{N}$ & $\mathrm{N}$ & $\mathrm{N}$ & $\mathrm{N}$ & NP & $\mathrm{N}$ & $\mathrm{N}$ & $\mathrm{N}$ & $\mathrm{NP}$ & ------ & ----- \\
\hline Mimosa pudica & Sensitiva & Herbácea & $\mathrm{N}$ & $\mathrm{N}$ & $\mathrm{N}$ & $\mathrm{N}$ & $\mathrm{PN}$ & $\mathrm{N}$ & $\mathrm{NP}$ & $\mathrm{NP}$ & NP & $\mathrm{N}$ & $\mathrm{P}$ & NP \\
\hline Stryphnodendron & Fava de paca & Arbóreo & ------ & ----- & ----- & ----- & ----- & $\mathrm{N}$ & $\mathrm{N}$ & ----- & ----- & & ----- & ----- \\
\hline \multicolumn{15}{|l|}{ Flacourtiaceae } \\
\hline Tipo indet. & & & ----- & $\mathrm{N}$ & ----- & $\mathrm{N}$ & $\mathrm{N}$ & $\mathrm{N}$ & $\mathrm{N}$ & $\mathrm{NP}$ & $\mathrm{N}$ & $\mathrm{P}$ & ------ & ----- \\
\hline \multicolumn{15}{|l|}{ Lamiaceae } \\
\hline Hyptis & & Herbácea & $\mathrm{PN}$ & $\mathrm{PN}$ & $\mathrm{N}$ & $\mathrm{N}$ & ------ & $\mathrm{N}$ & $\mathrm{N}$ & $\mathrm{N}$ & ----- & $\mathrm{N}$ & $\mathrm{NP}$ & NP \\
\hline \multicolumn{15}{|l|}{ Myrtaceae } \\
\hline Tipo indet. & & Arbóreo & $\mathrm{N}$ & $\mathrm{N}$ & $\mathrm{NP}$ & NP & $\mathrm{PN}$ & $\mathrm{N}$ & $\mathrm{N}$ & $\mathrm{NP}$ & ------ & $\mathrm{N}$ & ------ & ----- \\
\hline \multicolumn{15}{|l|}{ Poaceae } \\
\hline Zea mays & & Herbácea & ----- & ----- & $-\cdots--$ & $-\cdots---$ & ----- & ------ & ----- & ----- & $\mathrm{P}$ & $\mathrm{P}$ & ----- & ----- \\
\hline \multicolumn{15}{|l|}{ Rubiaceae } \\
\hline Borreria verticillata & Vassourinha & Herbáceo & $\mathrm{PN}$ & $\mathrm{PN}$ & $\mathrm{PN}$ & $\mathrm{PN}$ & $\mathrm{PN}$ & $\mathrm{N}$ & $\mathrm{N}$ & $\mathrm{N}$ & NP & $\mathrm{N}$ & $\mathrm{NP}$ & $\mathrm{PN}$ \\
\hline \multicolumn{15}{|l|}{ Turneraceae } \\
\hline Turnera ulmifolia & Chanana & Herbácea & ------ & ------ & ----- & $\mathrm{N}$ & $\mathrm{N}$ & $\mathrm{N}$ & $\mathrm{N}$ & ------ & ----- & ----- & ----- & ----- \\
\hline \multicolumn{15}{|l|}{ Urticaceae } \\
\hline Cecropia & Embaúba & Arbóreo & ------ & ----- & ----- & ----- & $\mathrm{P}$ & $\mathrm{P}$ & --.-- & ----- & ----- & ----- & ------ & $\mathrm{P}$ \\
\hline
\end{tabular}

todo o período de estudo, exceção abril e maio/2006, sendo classificados como PI em todas as avaliações. Os maiores percentuais médios ocorreram em outubro $(7,18 \%)$, dezembro $(7,21 \%)$ e janeiro $(8,27 \%)$. Os percentuais médios no período de produção foram $0,21 \%, 3,33 \%, 0,58 \%$ e $0,73 \%$ respectivamente em junho, julho, agosto e setembro. Apesar dos baixos percentuais esta família pode ser relevante. Segundo Ricardelli D’Albore (1992) e Piana (1997) citados por Maia et al. (2005), a família Asteraceae possui espécies normalmente sub-representadas no espectro polínico dos méis e podem ser responsáveis pela produção de méis monoflorais. Portanto, esta família pode ser considerada uma das mais utilizadas pelas abelhas no período de safra.

Os tipos polínicos anemófilos foram representados em Urticaceae e Poaceae. Urticaceae foi representada nas lâminas de mel pelo gênero Cecropia. Esta família ocorre abundantemente na vegetação secundária das matas úmidas do litoral e das serras (Lorenzi, 2000). O tipo polínico desta 
família foi crescente de agosto $(3,51 \%)$ a novembro/2005 $(47,09 \%)$ e, nos meses subsequentes ocorreu, na maioria das observações, como PI. Nas amostras de pólen ocorreu nos meses de dezembro/2005, janeiro e julho/2006. Este tipo polínico não é relevante na produção de mel por ser anemófilo, porém é caracterizado como importante fonte alimentícia para A. mellifera (Oliveira et al., 1998). O alto percentual de polen anemófilo nas amostras de mel pode estar relacionado com os picos de floração de espécies de Cecropia, que aumenta a dispersão dos tipos polínicos no ar, além das visitas espontâneas das abelhas para a coleta de pólen apícola.

A família Poaceae teve como principais representantes as espécies Brachiara sp e Zea mays, que também apresentam pólen anemófilo. A cultura do milho na localidade tem início com o período chuvoso, sendo uma importante atividade complementar para os apicultores e agricultores da região. Os tipos polínicos desta família foram observados nas lâminas de mel e pólen principalmente no período chuvoso (Tab. 1 e 2). Segundo Oliveira et al. (1998), esta espécie também funciona como uma importante fonte de alimento para as abelhas.

A família Lamiaceae foi representada na área em estudo por Hyptis atrorubens Poin., Hyptis lophanta Mart. ex Benth., Hyptis suaveolens (L.) Poit. e Leucas martinicensis (Jacq) W.T. Aiton. Devido a grande semelhança de seus tipos polínicos não foi possível discernir qual espécie realmente foi a maior responsável pelo mel avaliado; sendo especificado nas lâminas de mel e pólen como pertencente ao tipo Hyptis spp. Entretanto, em observações de campo no período de março a junho/2006 foi verificada a floração massificada de duas espécies: H. atrorubens e H. suaveolens, esta última, segundo Lorenzi (2000), está distribuída em todo o território brasileiro, onde ocorre espontaneamente em solos agrícolas, beira de estrada e terrenos baldios, sendo considerada planta daninha.

Nas amostras de pólen foi verificado que o tipo Hyptis ocorreu nos meses de agosto e setembro/2005, junho e julho/2006. Nas amostras de mel, este tipo polínico foi classificado como PI no período de setembro a abril, ou seja, baixos percentuais variando de 0,00 a $5,15 \%$; em maio (76,84\%) e junho $(65,94 \%)$ este tipo polínico apresentou altos percentuais, sendo classificado como PD, caracterizando mel monofloral e, de julho $(37,74 \%)$ a agosto $(19,46 \%)$ percentuais intermediário (Pólen Acessório). Desta forma as maiores contribuições desse gênero iniciam no mês de maio e decresce até agosto. Neste período ocorreram as maiores produções de mel claro, demonstrando a representatividade desta família no período de produção. Estes resultados são corroborados por Maia et al. (2005) em Portugal, onde observaram a família Lamiaceae com elevada produção de néctar com referência ao tipo Lavandula stoechas, sendo que esta espécie é monofloral na maioria das amostras de mel.

Fabaceae-Mimosoideae estava representada na região por Mimosa caesalpiniifolia Benth., Mimosa pudica L. e
Stryphnodendron sp. Nas amostras de mel os maiores percentuais médios ocorreram em novembro (6,5\%), março $(8,28 \%)$ e maio $(8,99 \%)$. Nos outros meses do estudo este tipo polínico foi classificado como pólen isolado (PI). O pólen de M. caesalpiniifolia também foi observado por Moreti et al. (2000) em análises de amostras de mel no município de Rio Real (BA).

Mimosa pudica estava representada em todas as amostras de mel. Segundo Oliveira et al. (1998), em análises polínicas das amostras de mel em área de floresta secundária no município de Igarapé-Açu (PA), foram identificadas cinco espécies de Fabaceae-Mimosoideae, entre as quais $M$. pudica foi intensamente visitada pelas abelhas durante todo o período de amostragem, destacando-se durante cinco meses como PD. Segundo Barth (1989), esta espécie é super-representada nas amostras de mel, pois são plantas fornecedoras de pequena quantidade de néctar e de muitos grãos de pólen. Nas amostras de pólen, $M$. pudica participou em seis dos 12 meses avaliados (Tab. 2). Nas amostras de mel esta espécie foi crescente de outubro/2005 a abril/2006, com percentuais médios máximos de $85,71 \%$ neste último e decresceu nos meses subseqüentes. As maiores frequências de $M$. pudica foram relacionadas ao período chuvoso, período de escassez de alimento para as abelhas, podendo-se considerar espécie importante na manutenção de colméias no período crítico, tendo-se como referência os altos percentuais encontrados nas amostras de mel. Em Santa Luzia do Paruá, a alta frequência dessa espécie no período chuvoso pode estar relacionada à inexistência de uma espécie mais atrativa ou mesmo à grande disponibilidade desta espécie na região.

Stryphnodendron esteve presente em janeiro e fevereiro na amostra de mel como PI no início das chuvas, não havendo ocorrência nas amostras de pólen. Resultado condizente com Franke (1999) que identificou e caracterizou três espécies do gênero Stryphnodendron como plantas melíferas no estado do Acre.

Entre as Myrtaceae, foram identificados os tipos polínicos Psidium (goiaba do mato) e Syzygium (azeitona preta). Nas amostras de pólen, este tipo polínico ocorreu em outubro, novembro, dezembro/2005 e março/2006. Nas amostras de mel foi constante em todo o período de estudo como pólen isolado (PI), com os maiores percentuais médios em setembro (5,06\%), novembro (12,68\%) e dezembro (12,68\%). No trabalho de Marchini et al. (2001), Myrtaceae tipo 1 foi importante no calendário de florescimento das plantas de interesse apícola inventariadas no campus da ESALQ/USP, em Piracicaba (São Paulo), no período de 1994 a 1997.

Dentre as Rubiaceae, merecem destaque os tipos polínicos Borreria latifolia, Borreria verticillata, Diodia alata e Mitracarpus hirsutus. Oliveira et al. (1998) constataram que a família Rubiaceae apresentou três espécies presentes nas amostras de mel, das quais $B$. verticillata foi a mais importante durante 12 meses (agosto a março/1995 e maio 
a novembro/1996). Neste trabalho, foi reconhecido o tipo Borreria nas amostras de mel.

Este tipo polínico foi observado em todo período de estudo, sendo que suas maiores contribuições foram registradas em setembro $(29,19 \%)$ e outubro (18,84\%). A contribuição nesse período revela a sua importância no período seco. Também foram observados altos percentuais em dezembro $(44,18 \%)$, janeiro $(18,98 \%)$ e fevereiro $(10,35 \%)$, indicando sua participação na pequena produção que ocorre no início das chuvas. Na produção de pólen apícola este gênero também é relevante, ocorrendo em oito dos 12 meses avaliados (Tab. 2).

Sterculiaceae esteve representada na região em estudo por Waltheria indica L. e Waltheria tomentosa (J.R. Forster e G. Forster) H. St. John. Apesar do tipo polínico dessa família não ter sido encontrado no mel, há relatos de seu potencial apícola. Aguiar et al. (2002) verificaram sua representatividade entre plantas visitadas por A. mellifera, sendo considerada com $17 \%$ das visitas realizadas.

As famílias Amaranthaceae, Euphorbiaceae, Flacourtiaceae, Turneraceae e os cinco tipos indeterminados mais importantes apresentaram contribuições de forma isolada nos apiários, com baixa frequencia e constância no período de estudo nas amostras de mel e pólen (Tab. 1 e 2), sendo que Turneraceae e os cinco tipos indeterminados ocorreram apenas nas amostras de pólen. Amaranthaceae e Turneraceae apresentaram-se como PI no período de estudo. O tipo polínico de Euphorbiaceae apareceu com quantidades de PI com mais constância, porém em setembro apresentou percentuais de $61,59 \%$. Flacourtiaceae também apresentou um percentual diferenciado, no mês de janeiro com $74,74 \%$ e percentuais médios mais baixos nos demais meses. Outros tipos polínicos que ocorrem de forma isolada foram os tipos indeterminados no período de produção. Percentuais isolados e diferenciados também foram observados nos trabalhos de Luz et al. (2007) com Castanea que ocorre num único mês com percentual de 79,2\%.

A vegetação da região em estudo é caracterizada como vegetação secundária. Segundo Oliveira et al. (1998), existe boa atividade apícola em áreas de floresta secundária com diferentes idades de pousio. De forma geral a região apresenta boas características de pasto apícola, com uma safra no meio do ano e uma pequena produção no início das chuvas, situação esta que aliada a um bom manejo permite a sustentabilidade e boas produções nos apiários. Os tipos polínicos que mais se destacaram nas amostras de mel foram Hiptis, Mimosa caesalpiniifolia, M. pudica e Borreria e tipo indeterminado da família Asteraceae.

\section{Agradecimentos}

Ao CNPq, pelos recursos financeiros aportados ao Projeto (CNPq/Processo no 478777/2004-3) e Concessão de Bolsa de Iniciação Científica. Aos apicultores: Mauro Costa, Ezequias Costa Brito, Iranir Nunes Brito, Raimundo Costa Lino, Gustavo Lustosa Mello, Ranieri, Antonio do Sindicato e Davide.

\section{Referências bibliográficas}

Aguiar, C.M.L.; Monteiro, V.M.; Santos, G.M.M.; Resende, J.J.; França, F. \& Melo, E. 2002. Plantas visitadas por Apis mellifera L. (Hymenoptera, Apidae) em uma área de caatinga em Itatim, Bahia, Brasil. Sitientibus Série Ciências Biológicas 2(1/2): 29-33.

APG III. 2009. An update of the Angiosperm Phylogeny Group classification for the orders and families of flowering plants: APG III. Botanical Journal of the Linnean Society 161(2): 105-121.

Barth, O.M. 1989. O pólem no mel brasileiro. Rio de Janeiro, Gráfica Luxor.

Barth, O.M. 2004. Melissopalynology in Brazil: a review of pollen analysis of honeys, propolis and pollen loads of bees. Piracicaba: Sciencia Agrícola 61(3): 342-350

Barth, O.M. 2005. Análise polínica de mel: avaliação de dados e seu significado. Mensagem Doce 81, www.apacame.org.br (Acesso: em 17/10/ 2006).

Barth, O.M.; Justo, R.L.; Barros, M.A. 1998. Catálogo sistemático do pólen das plantas arbóreas do brasil meridional. XXX: meliaceae. Revista Brasileira de Biologia 58(3): 497-509.

Carreira, L.M.M. \& Jardim, M.A.G. 1994. Análise polínica dos méis de alguns municípios do Estado do Pará - II. Boletim do Museu Paraense Emílio Goeldi, Série Botânica 10(1): 1-19.

Carreira, L.M.M.; Jardim, M.A.G.; Moura, C.O.; Pontes, M.A.O. \& Marques, R.V. 1986. Análise polínica nos méis de alguns municípios do Estado do Pará. Pp. 79-84. In Anais do $1^{\circ}$ Simpósio Internacional do Trópico Úmido. CPATU, EMBRAPA, Belém, v. II.

Carvalho, C.A.L. de \& Marchini, L.C. 1999. Plantas visitadas por Apis mellifera L. no vale do rio Paraguaçu, Município de Castro Alves, Bahia. Revista Brasileira de Botânica 22(2): 333-338.

Cronquist, A. 1981. An integrated system of classification of flowerinf plants. New York, Columbia University Press.

Erdtman, G. 1952. Pollen morphology and plant taxonomy: Angiosperms. Stockholm, Almquist e Wiksell.

Fernandes, A. 2007. Fitogeografia Brasileira - Fundamentos Fitogeográficos: Fitopaleontologia, Fitoecologia, Fitossociologia, Fitocorologia. 1a Parte - $3^{\text {a }}$ ed. Revisada. Fortaleza, Edições UFC

Ferreira, M.B. 1981. Plantas apícolas no Estado de Minas Gerais. Informe Agropecuário 7: 40-47.

Franke, I.L. 1999. Principais usos e serviços de arvores e arbustos promissores que ocorrem em pastagens no estado do Acre. Comunicado técnico. Embrapa Acre, 106: 1-6.

Geplan/Uema. 2002. Atlas do Maranhão. 2 ed. São Luis, GEPLAN.

Lorenzi, H. 2000. Plantas Daninhas do Brasil, Terrestres, Aquáticas, Parasitas e Tóxicas. 3 ed. Nova Odessa, Instituto Plantarum de Estudos da Flora Ltda.

Luz, C.F.P. da; Thomé, M.L. \& Barth, O.M. 2007. Recursos tróficos de Apis mellifera L. (Hymenoptera, Apidae) na região de Morro Azul do Tinguá, Estado do Rio de Janeiro. São Paulo. Revista Brasileira de Botânica 30(1): 47-65.

Maia, M.; Russo-Almeida, P.A.; Pereira, J. O. 2005. Caracterização do espectro polínico dos méis do Alentejo (Portugal). Lisboa. Silva Lusitana 13(1): 95-103.

Marchini, L.C.; Teixeira, E.W.; Silva, E.C.A.; Rodrigues, R.R.; Souza, V.C. 2001. Plantas visitadas por abelhas africanizadas em duas localidades do estado de São Paulo. Sciencia Agricola 58(2): 413-420.

Maurizio, A. \& Louveaux, J. 1965. Pollen de plantes melliferes d'Europe. Paris, Union des Groupments Apicoles Français.

Mendonça, K.; Marchini, L.C.; Souza, B.A.; Almeida-Anacleto, D.; Moreti A.C.C.C. 2008. Plantas Apícolas de Importância para Apis mellifera L. (Hymenoptera: Apidae) em Fragmento de Cerrado em Itirapina, SP. Neotropical Entomology 37(5): 513-521.

Moreti, A.C.C.C.; Carvalho, C.A.L.; Marchini, L.C. \& Oliveira, P.C.F. 2000. Espectro Polínico de Amostras de Mel de Apis mellifera L., coletadas na Bahia. Campinas: Bragantia 59(1): 1-6.

Muniz, F.H.; Brito, É.R. 2007. Levantamento da flora apícola do município de Itapecuru-Mirim, Maranhão. Revista Brasileira de Biociências 5(supl. 1): 111-113.

Oliveira, F.P.M.; Carreira, L.M.M. \& Jardim, M.A.A. 1998. Caracterização Polínica do mel de Apis mellifera L. em área de Floresta Secundária no Município de Igarapé-Acu-Pará. Boletim do Museu Paraense Emílio Goeldi, Série Botânica 14(2): 122-136. 
Pereira, F.M.; Lopes, M.T.R.; Camargo, R.C.R.; Vilela, S.L.O. 2003 Produção de Mel. Embrapa Meio-Norte: Sistema de Produção 3 http://sistemasdeproducao.cnptia.embrapa.br/FontesHTML/Mel/ SPMel/colheita.htm (Acesso em: 30/11/2010).

Ramalho, M.; Kleinert-Giovannini, A.; Imperatriz-Fonseca, V.L. 1990 Important bee plants for stingless bees (Melipona and Trigonini) and africanized honeybees (Apis mellifera) in neotropical habitats: a review. Apidologie 21: 469-488.

Reis, V.D.A. \& Cosmastri-Filho, J.A. 2003.Importância da Apicultura no Pantanal Sul-Mato-Grossense. Documentos 56. Corumbá, Embrapa Pantanal.
Roubik, D.W.; Patiño, J.E.M., 2003. Pollen and Spores of Barro Colorado Island. Smithsonian tropical research institute. Panamá, http:// striweb.si.edu/roubik/ (Acesso em 17/12/ 2006).

Salomé, J. A. \& Orth, A. I. 2003. A flora apícola catarinense e sua ação sobre as colméias APACAME. Mensagem Doce, 71. http://www.apacame. org.br/index1.htm// (Acesso 15/07/ 2007).

Santos, R.F.; Kill, L.H.P. \& Araújo, J.L.P. 2006. Levantamento da flora melífera de interesse apícola no município de Petrolina-PE. Mossoró: Caatinga 19(3) 221-227. 